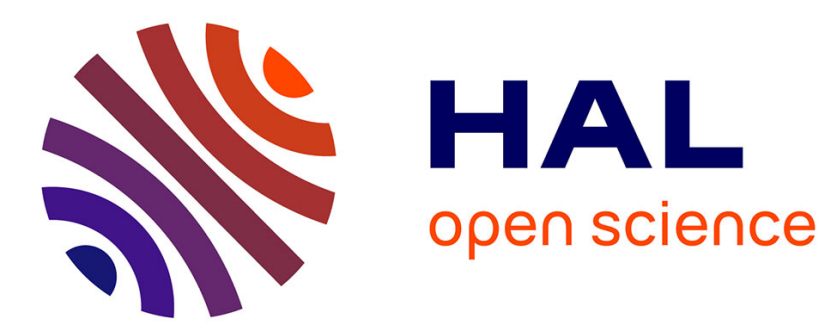

\title{
Endogenous formation of alliances in conflicts
}

Francis Bloch

\section{To cite this version:}

Francis Bloch. Endogenous formation of alliances in conflicts. 2009. hal-00435387

\section{HAL Id: hal-00435387 \\ https://hal.science/hal-00435387}

Preprint submitted on 24 Nov 2009

HAL is a multi-disciplinary open access archive for the deposit and dissemination of scientific research documents, whether they are published or not. The documents may come from teaching and research institutions in France or abroad, or from public or private research centers.
L'archive ouverte pluridisciplinaire HAL, est destinée au dépôt et à la diffusion de documents scientifiques de niveau recherche, publiés ou non, émanant des établissements d'enseignement et de recherche français ou étrangers, des laboratoires publics ou privés. 


\title{
ECOLE POLYTECHNIQUE
}

CENTRE NATIONAL DE LA RECHERCHE SCIENTIFIQUE

\section{ENDOGENOUS FORMATION OF ALLIANCES IN CONFLICTS}

\author{
Francis BLOCH
}

October 2009

Cahier $n^{\circ}$ 2009-46

\section{DEPARTEMENT D'ECONOMIE}

Route de Saclay

91128 PALAISEAU CEDEX

(33) 169333033

http://www.enseignement.polytechnique.fr/economie/

mailto:chantal.poujouly@polytechnique.edu 


\title{
Endogenous formation of alliances in conflicts
}

\author{
Francis Bloch*
}

October 11, 2009

\begin{abstract}
This paper studies the endogenous formation of alliance in conflicts offering a survey of the recent literature and providing new results. We analyze the effect of group sizes on conflict, study endogenous alliance formation in a general model of conflict with linear technology and discuss recent developments of the theory of alliance formation, involving the determination of sharing rules inside the alliance and dynamic alliance formation in nested conflicts.

JEL Classification Numbers: D74, D72, C72

Keywords: alliance formation, conflicts, rent-seeking contest, collective action, the paradox of group size, sharing rules, nested conflicts
\end{abstract}

*Department of Economics, Ecole Polytechnique, Palaiseau, France. tel: +33 (1) 693330 45, email: francis.bloch@polytechnique.edu 


\section{Introduction}

In many situations of conflict, agents pool resources and efforts to fight their adversaries. Alliances have often been formed to win wars, political elections or rentseeking contests. The history of warfare is a succession of alliances forming and collapsing over time, from the alliances between warlords in Ancient China to the intricate systems of alliances in XIXth century Europe. Recent history offers a testimony of the importance of alliances in international relations. The alliance formed between the United States, the Soviet Union and Britain during the Second World War collapsed and was followed by two different Blocs during the Cold War, only to be succeeded by the collapse of the Soviet Bloc and the emergence of new forms of regional alliances.

In order to understand the formation of alliances in conflict, economists and political scientists have developed a theoretical apparatus borrowing concepts from public economics, public choice and game theory. Following the seminal paper by Olson and Zeckhauser (1966), an important strand of the literature, reviewed by Sandler (1993) and Hartley and Sandler (2001) has focused on the public good problem associated to the alliance. In an alliance, parties have an incentive to free-ride on the efforts and resources of other members of the alliance, and small parties have a tendency to rely on the efforts of larger parties. As a consequence, the total effort of the alliance is suboptimal - the classical public good problem - and large parties bear a disproportionate share of the cost of the alliance - the exploitation problem faced for example by the United States in NATO and other international organizations.

This free-riding problem had already been emphasized in Olson (1965)'s earlier theory of collective action. While Olson and Zeckhauser (1966) focus on the freeriding problem in a single alliance faced with an exogenous threat, subsequent work has considered conflict across different groups, each of them being plagued by the free-riding problem. In this context, Olson (1965) postulated that small groups should be more effective and more likely to win conflicts, as the free-riding problem they face is less acute than in larger groups. This "paradox of group size" has generated a sizeable literature in political science and economics, which attempts to formalize Olson (1965)'s ideas and delineate conditions under which small groups are more effective in conflict.

Tullock (1967)'s formalization of rent-seeking contests provides the framework in which Olson (1965)'s ideas can be expressed. However, the structure of the probabilistic model of conflict of Tullock (1967) is unexpectedly complex, and the comparative statics results needed to establish whether small groups are more effective, remain elusive. Early work by Chamberlin (1974), Mac Guire (1974), Sandler (1992) and others established that, in some specific contexts, small groups are more effective when the conflict involves a rival private good, whereas large groups are more effective when agents fight over a nonrival public good.

Tullock (1980), Katz and Tokatlidu (1996), Baik and Lee (1997) and Wärneryd (1998) analyze two-group contests with different specifications of the prizes, and ob- 
tain partial comparative statics results on the sizes of the groups, suggesting again that small groups are more effective, and that total expenditures on conflict are higher when the two groups are more symmetric. Esteban and Ray (1999) and (2001) revisit Olson (1965)'s arguments in a more general model of conflict, emphasizing the complexity of the noncooperative game of conflict played among groups of different sizes. Esteban and Ray (2001) in particular show that the "common wisdom" according to which small groups are always more effective in conflicts over private goods does not necessarily hold when one considers general conflict technologies.

The comparative statics analysis of the effect of group sizes in conflict is a necessary building block to understand the formation of alliances. Using recent advances in the theory of coalition formation, Skaperdas (1998), Tan and Wang (1997), Esteban and Sakovics (2003), Garfinkel (2004), Bloch, Sanchez-Pages and Soubeyran (2006) and Sanchez-Pages (2007) attempt to endogenize the formation of alliances in model of contests. While each of the papers focuses on a different specification and different procedures of coalition formation, two general intuitions emerge from this strand of the literature.

First, as shown by Skaperdas (1998), Tan and Wang (1997)and Esteban and Sakovics (2003) in three-player models, parties have no incentive to form a two-player alliance against the third unless the formation of the alliance generates synergies which enhance the winning probability of the alliance. This negative result, labeled by Konrad (2009) "the paradox of alliance formation", relies on a very basic intuition. Inside an alliance, agents have less incentive to provide effort for two reasons: first, they only obtain a fraction of the prize instead of its full value because they still have to share the prize with the other alliance member (possibly having to fight in a second contest with her), and second the choice of effort inside the alliance is subject to free-riding. The paradox of alliance formation poses a challenge to economists, as one observes alliances forming even in the absence of synergies.

The second message of the literature is that the grand coalition plays a special role. In the grand coalition, the prize is peacefully shared among alliance members and no resources are wasted on conflict. There is a significant, qualitative gap between the payoff of players in the grand coalition and any other coalition structure. In a model where all coalitions may possibly form, Bloch, Sanchez-Pages and Soubeyran (2006) and Sanchez-Pages (2007) observe that the special role of the grand coalition implies that it will often emerge as the equilibrium of the process of alliance formation. This result poses another challenge to economists, who need to explain why universal peace does not always prevail, and why smaller, competing alliances form.

The economic literature on alliance formation has developed along two other themes. First, following Nitzan (1991a), attention has been focused on sharing rules within the alliance. Nitzan (1991a) proposes a sharing rule which is a convex combination of the egalitarian rule (a "soft" rule which does not give high incentives to group members) and the relative effort rule (a "hard rule" which, as in a rat race, induces group members to exert high effort). Nitzan (1991a) and (1991b) (amended 
by Davis and Reilly (1999) and Ueda (2002)) computes the equilibrium level of conflict under different rules. Lee (1995), Baik and Shogren (1995), Baik and Lee (1997), Noh (1999) and (2002) endogenize the sharing rule and the sizes of groups. One of the most interesting outcomes of their analyses is that, in a contest among two groups of equal size, both groups have an incentive to choose the hard relative effort rule, even though they would both be better off with the soft egalitarian rule - a classical instance of the prisoner's dilemma. This result, is reminiscent of models of strategic delegation in games: both groups have an incentive to choose a hard rule (or a tough delegate), in order to increase their winning probability, even though this will result in large wasteful expenditures on conflict.

The second theme is the distinction between static and dynamic group contests. In a static group contest, the prize is shared among alliance members immediately ; in a dynamic group contest (or "nested contest"), members of an alliance award the prize by a succession of contests, until only two contestants remain in the end. The dynamic model of contest has only received attention in recent years - Skaperdas (1997), Tan and Wang (1997), Wärneryd (1998), Esteban and Sakovics (2003), Garfinkel (2004) and Kovenock and Konrad (2008) propose different specifications of this model - and has only been studied in very restrictive contexts.

The rest of the chapter is organized as follows. The next Section discusses the effect of group sizes on conflict in a general model encompassing most of the existing literature. Section 3 studies general models of endogenous alliance formation based on recent advances in game theory. Section 4 provides a detailed analysis of sharing rules inside the alliance. Section 5 is devoted to models of dynamic contests and alliance formation. Finally, we conclude and provide directions for future research in the last Section.

\section{Conflict and group sizes}

As a preliminary to the study of endogenous alliance formation, we need to understand how levels of conflict and the utilities of the players depend on the structure and sizes of the alliances. In this Section, we consider a fixed structure of $m$ alliances, $\mathcal{A}=\left\{A_{1}, \ldots, A_{m}\right\}$ and investigate (i) whether small groups or large groups are more likely to win the conflict in the fixed alliance structure $\mathcal{A}$ and (ii) how changes in the alliance structure affect the level of conflict and the utilities of the players.

\subsection{A general model of group conflict among symmetric agents}

In order to present Olson (1965)'s argument on the effectiveness of small groups, we introduce a general model of conflict encompassing most studies of group contests. We consider symmetric players $i=1,2, \ldots n$ and let $s_{i}$ denote each player's investment in conflict. We suppose that agents have an identical increasing, convex, cost function $c\left(s_{i}\right)$. Players form alliances, and the probability that alliance $A_{j}$ wins the contest 
is given by the familiar Tullock (1980) logistic contest function:

$$
p_{j}=\frac{\sum_{i \in A_{j}} s_{i}}{\sum_{i} s_{i}}
$$

if $\sum_{i} s_{i} \neq 0$, and $p_{j}=\frac{1}{m}$ otherwise. ${ }^{1}$ We suppose that the sharing rule inside each alliance $A_{j}$ is independent of the investments of the players in the inter-alliance conflict, $\mathbf{s}=\left(s_{1}, \ldots, s_{n}\right)$, and treats all agents symmetrically. ${ }^{2}$ Hence, the value of the prize to any member of an alliance $A$ can be expressed as a function $V(a)$, which only depends on the size of the alliance $A$. We distinguish between two cases: the public good case, where $V(a)$ is nondecreasing and the private good case where $V(a)$ is non-increasing. ${ }^{3}$

This broad specification covers both private and public goods, and situations where members of the alliance coordinate their investments or not. Focussing on two extreme examples, consider first a situation where alliance members coordinate their investments to obtain a public prize. The average utility of an alliance member can be expressed as:

$$
\begin{aligned}
U_{i} & =\max _{s_{i, i \in A_{j}}} \frac{\sum_{i \in A_{j}} s_{i}}{\sum_{i} s_{i}} V-\frac{\sum_{i \in A_{j}} c\left(s_{i}\right)}{a_{j}}, \\
& =\max _{s} \frac{a_{j} s}{\sum_{i} s_{i}} V-c(s),
\end{aligned}
$$

Assuming that the optimal investment $s$ is interior, it is characterized by the first order condition:

$$
a_{j} V \frac{\sum_{k \notin A_{j}} s_{k}}{\left(\sum_{i} s_{i}\right)^{2}}-c^{\prime}(s)=0 .
$$

a formula yielding the same investment level as if each alliance member received a share of the prize $V\left(a_{j}\right)=V a_{j}$. Consider by contrast another model where agents in a group obtain a private prize, which is reallocated according to a subsequent intra-alliance contest where agents have a linear investment technology as in Katz and Tokatlidu (1996) and Garfinkel (2004). In the second stage contest, each agent gets a utility:

\footnotetext{
${ }^{1}$ See Skaperdas (1996) for an axiomatization of contest success functions.

${ }^{2}$ We discuss conflict with sharing rules which depend on the investments in inter-alliance conflict and group conflict among asymmetric agents in Section 4.

${ }^{3}$ Group competition with public goods has been introduced by Katz, Nitzan and Rosenberg (1990).
} 


$$
\begin{aligned}
U_{i} & =\max s_{i} \frac{s_{i}}{\sum_{i} s_{i}} V-s_{i}, \\
& =\frac{1}{a_{j}}-\frac{a_{j}-1}{a_{j}^{2}}, \\
& =\frac{1}{a_{j}^{2}} .
\end{aligned}
$$

Hence, in the first stage inter-alliance contest, an agent in an alliance of size $a_{j}$ anticipates to receive a share of the prize $V\left(a_{j}\right)=\frac{V}{a_{j}^{2}} \cdot 4$

\subsection{Two-group conflict}

We first analyze a situation where two groups $A_{1}$ and $A_{2}$ of sizes $a_{1}$ and $a_{2}$ compete in the contest. The two-group model was discussed in Tullock (1980)'s original paper has been analyzed by Katz and Tokatlidu (1996), Baik and Lee (1997) and Wärneryd (1998)). As noted by Esteban and Ray (1999), the two-group model is a special case, and some of the intuitions gained in the two-group model do not carry over to structures with an arbitrary number of alliances. We denote by $S_{1}=a_{1} s_{1}$ the total investment of good 1 , by $S_{2}=a_{2} s_{2}$ the total investment of good 2 and by $S=S_{1}+S_{2}$ the total resources spent in conflict. We first establish existence and uniqueness of equilibrium in any two-group contest:

Proposition 1 In any two-group contest, there exists a unique interior equilibrium, characterized by the first order conditions:

$$
\begin{aligned}
& V\left(a_{1}\right) S_{2}-c^{\prime}\left(\frac{S_{1}}{a_{1}}\right) S^{2}=0 \\
& V\left(a_{2}\right) S_{1}-c^{\prime}\left(\frac{S_{2}}{a_{2}}\right) S^{2}=0 .
\end{aligned}
$$

Existence of equilibrium relies on classical fixed-point arguments, as in Esteban and Ray (1999). To show uniqueness of the interior equilibrium, we first compute the derivative of the best response functions $\phi_{1}\left(S_{2}\right)$ and $\phi_{2}\left(S_{1}\right)$ :

\footnotetext{
${ }^{4}$ The two sharing rules $V\left(a_{j}\right)=V a_{j}$ and $V\left(a_{j}\right)=\frac{V}{a_{j}^{2}}$ represent the two polar cases for reasonable sharing rules. Other usual sharing rules include the public good function $V\left(a_{j}\right)=V$ and the private good egalitarian sharing rule $V\left(a_{j}\right)=\frac{V}{a_{j}}$.
} 


$$
\begin{aligned}
\phi_{1}^{\prime}\left(S_{2}\right) & =\frac{V\left(a_{1}\right)-2 c^{\prime}\left(\frac{S_{1}}{a_{1}}\right) S}{\left(S\left(2 c^{\prime}\left(\frac{S_{1}}{a_{1}}\right)+c^{\prime \prime}\left(\frac{S_{1}}{a_{1}}\right) \frac{S}{a_{1}}\right)\right.}, \\
& =\frac{c^{\prime}\left(\frac{S_{1}}{a_{1}}\right)\left(S_{1}-S_{2}\right)}{S_{2}\left(2 c^{\prime}\left(\frac{S_{1}}{a_{1}}\right)+c^{\prime \prime}\left(\frac{S_{1}}{a_{1}}\right) \frac{S}{a_{1}}\right)}, \\
\phi_{2}^{\prime}\left(S_{1}\right) & =\frac{c^{\prime}\left(\frac{S_{2}}{a_{2}}\right)\left(S_{2}-S_{1}\right)}{S_{1}\left(2 c^{\prime}\left(\frac{S_{2}}{a_{2}}\right)+c^{\prime \prime}\left(\frac{S_{2}}{a_{2}}\right) \frac{S}{a_{2}}\right)} .
\end{aligned}
$$

This computation shows that group investments are neither strategic substitutes nor complements: the best response function $\phi_{i}\left(S_{j}\right)$ is increasing in $S_{j}$ when $S_{i}>S_{j}$ and decreasing in $S_{j}$ when $S_{j}>S_{i} .{ }^{5}$ Figure 1 illustrates the best responses and the equilibrium, noting that $\phi_{i}(0)=\epsilon>0$ for $i=1,2$.

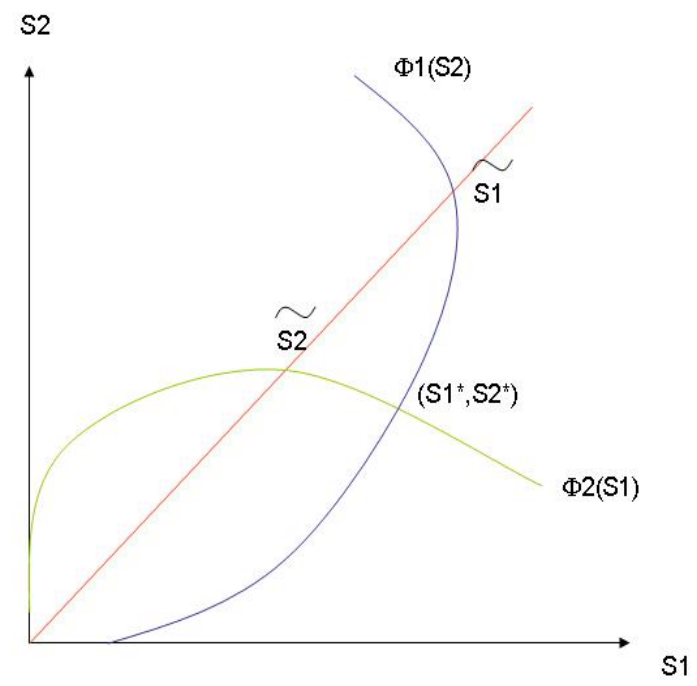

Figure 1: BeSt RESPONSE FUnCtions in THE TWO-GROUP CONTEST

\footnotetext{
${ }^{5}$ In that respect, contests are very different from other "aggregative games" where utilities depend on own choice and an aggregator of choices of all agents, like Cournot games and public good games (strategic substitutes) and Bertrand games with differentiated commodities (strategic complements).
} 
Figure 1 also indicates why equilibrium in a two-group contest must be unique: if an equilibrium $\left(S_{1}^{*}, S_{2}^{*}\right)$ with $S_{1}^{*}>S_{2}^{*}$ exists, as in the graph, there cannot be any other equilibrium in the region where $S_{1}>S_{2}$, as the best response function $\phi_{1}\left(S_{2}\right)$ is increasing, and the best response function $\phi_{2}\left(S_{1}\right)$ is decreasing. Furthermore, if we let $\tilde{S}_{1}$ and $\tilde{S}_{2}$ denote the intersection points between the best response functions and the 45 degree line, the existence of an equilibrium with $S_{1}^{*}>S_{2}^{*}$ necessarily implies that $\tilde{S}_{1}>\tilde{S}_{2}$, precluding the existence of another equilibrium in the region where $S_{1}<S_{2}$.

Using equations (1) and (2), we compute:

$$
\frac{c^{\prime}\left(s_{1}\right) s_{1}}{c^{\prime}\left(s_{2}\right) s_{2}}=\frac{\frac{V\left(a_{1}\right)}{a_{1}}}{\frac{V\left(a_{2}\right)}{a_{2}}} .
$$

As $c^{\prime}(s) s$ is increasing we obtain:

Remark 1 If $\frac{V(a)}{a}$ is non-increasing, individual investments are larger in smaller groups.

Remark 1 does not give any indication on the winning probabilities of the large and small groups, which depend on total group investments $S_{1}$ and $S_{2}$. We can similarly write

$$
\frac{S_{1}}{S_{2}}=\frac{\frac{V\left(a_{1}\right)}{c^{\prime}\left(s_{1}\right)}}{\frac{V\left(a_{2}\right)}{c^{\prime}\left(s_{2}\right)}} .
$$

implying that

Remark 2 If $V(a)$ is nondecreasing, group investments are larger for larger groups.

Remark 2 shows that the paradox of small groups never arises when players fight about a public good. Following Esteban and Ray (2001), this result can actually be extended by considering the family of iso-elastic cost functions $c(s)=s^{\alpha}$ for $\alpha>1$. For these cost functions, we obtain:

$$
\frac{S_{1} c\left(S_{1}\right)}{S_{2} c\left(S_{2}\right)}=\frac{a_{1}^{-\alpha} V\left(a_{1}\right)}{a_{2}^{-\alpha} V\left(a_{2}\right)}
$$

so that

Remark 3 If cost functions are iso-elastic and given by $c(s)=s^{\alpha}$, and $V(a) a^{-\alpha}$ is nondecreasing, group investments are larger for larger groups.

Remark 3 illustrates a trade-off between the curvatures of the cost and sharing rules in the determination of the effectiveness of large groups. If costs become more 
convex, there is a broader range of sharing rules for which large groups are more effective than small groups. Notice however that while remarks 2 and 3 only provide sufficient conditions under which large groups are more likely to win the conflict, but do not clearly delineate when large groups or small groups are more effective. ${ }^{6}$

Alternatively, we can study which groups are more effective by considering a fixed society of $n$ agents divided into two groups of sizes $a$ and $n-a$, and letting $a$ vary between 1 and $n$. Using the techniques of comparative statics in games introduced by Dixit (1986), we compute in the Appendix exact conditions under which group investment is increasing and decreasing in $a$.

Proposition 2 If $\inf _{a} \frac{a V^{\prime}(a)}{V(a)} \geq \sup _{s} \frac{-s c^{\prime \prime}(s)}{c^{\prime}(s)}$, then, for $a \geq \frac{n}{2}$, group investments of the large group, $S_{a}$ are increasing in a. If $\sup _{a} \frac{a V^{\prime}(a)}{V(a)} \leq \inf _{s} \frac{-s c^{\prime \prime}(s)}{c^{\prime}(s)}$, then for $a \leq \frac{n}{2}$, group investments of the small group $S_{a}$ are decreasing in a.

Proposition 2 provides another illustration of the trade-off between the curvature of the cost and sharing rules. For iso-elastic costs, $c(s)=s^{\alpha}$, $\inf _{s} \frac{-s c^{\prime \prime}(s)}{c^{\prime}(s)}=$ $\sup _{s} \frac{-s c^{\prime \prime}(s)}{c^{\prime}(s)}=1-\alpha$, and group investments are increasing in $a$ for large groups whenever $\frac{a V^{\prime}(a)}{V(a)} \geq 1-\alpha$, while group investments of small groups are decreasing in $a$ whenever $\frac{a V^{\prime}(a)}{V(a)} \leq 1-\alpha$.

\subsection{Conflict among multiple symmetric groups}

With more than two groups, the analysis of conflict becomes much more complex, and comparative statics results can only be obtained in a few special cases. We report results in the case of conflict among $k \geq 2$ symmetric groups of the same size $a=\frac{n}{k}$.

With $k$ symmetric groups, the unique symmetric equilibrium is characterized by

$$
V\left(\frac{n}{k}\right)(k-1)-c^{\prime}\left(\frac{S k}{n}\right) k^{2} S=0 .
$$

A direct computation shows that

$$
\begin{aligned}
\operatorname{sign} \frac{\partial S}{\partial k}= & \operatorname{sign}\left\{-\frac{n}{k^{2}} V^{\prime}\left(\frac{n}{k}\right)(k-1)+V\left(\frac{n}{k}\right)\right. \\
& \left.-\frac{S}{n} c^{\prime \prime}\left(\frac{S k}{n}\right) k^{2} S-2 k S c^{\prime}\left(\frac{S k}{n}\right) S\right\} .
\end{aligned}
$$

leading to the following result:

\footnotetext{
${ }^{6}$ An exact characterization of situations where small groups are more or less effective can be obtained in special cases, as in Esteban and Ray (2001) for quadratic costs and values which are convex combinations of $V$ and $\frac{V}{a}$, in Bloch et al. (2006) for quadratic costs and the value $\frac{V}{a}$ and in Sanchez Pages (2007) for linear cost functions.
} 
Proposition 3 In the case of public goods (when $V(a)$ is nondecreasing), an increase in $k$ results in a decrease in the symmetric group investment $S$. In the case

of private goods, when $\left.\inf _{a} \frac{a V^{\prime}(a)}{V(a)} \leq 1-\sup _{s} \frac{s c^{\prime \prime}(s)}{c^{\prime}(s)}\right)$, an increase in $k$ results in an increase in the symmetric group investment $S$.

Proposition 3 illustrates again the tension between the sharing and cost rules in the comparative statics on group investments: with public goods, fragmentation unambiguously results in a decrease in group investment ; with private goods, if the curvature of the cost function with respect to the sharing rule is not too high, an increase in fragmentation yields an increase in group investment. For example, with an iso-elastic cost function $c(s)=s^{\alpha}$, group investment increases with $k$ if $\frac{a V^{\prime}(a)}{V(a)} \leq-\alpha$.

The study of comparative statics of group sizes on investments leads us to the following conclusions, which form a useful starting block for the analysis of endogenous alliance formation. (i) For public goods (when $V(a)$ is nondecreasing), larger groups invest more, and group investment is increasing in group size. As individual investments are smaller for large groups, the utility of members of large groups is higher, and players' utilities are increasing in the size of the group they form. (ii) For private goods, when the sharing rule decreases slowly with respect to the cost function, (i.e. when $\inf _{a} \frac{a V^{\prime}(a)}{V(a)} \geq \sup _{s} \frac{-s c^{\prime \prime}(s)}{c^{\prime}(s)}$ ), the conflict resembles a public good conflict, and group investments are higher for large groups. When, on the other hand, the sharing rule decreases rapidly with respect to the cost function, small groups invest more, fragmentation increases the level of conflict, and the utility of members of small and large groups can no longer be compared.

\section{Endogenous alliance formation}

We now analyze players' incentives to form groups prior to the conflict. The study of endogenous alliance formation in conflict is complicated by the fact that players' utilities depend on the entire alliance structure formed, $\mathcal{A}$, and not only on the alliance $A$ they belong to. We need to analyze models of coalition formation with externalities (or in partition function form), where players' incentives depend on the coalitions formed by other players.

\subsection{Models of alliance formation with externalities}

The recent literature on coalition formation with externalities (Bloch (1996), Yi (1997), Ray and Vohra (1999)) discusses different models of endogenous coalition formation. The open membership game is a process by which all agents simultaneously announce a message $m_{i}$ in some sufficiently rich message space $M$, and alliances are formed among all agents who have announced the same address. Hart and Kurz (1983) analyze two exclusive membership games where all agents simultaneously announce a coalition $C_{i}$ to which they belong. In the $\gamma$ version of the game, coalition $C$ 
is formed if and only if $C_{i}=C$ for all $i \in C$. In the $\delta$ version of the game, coalition $C$ is formed if and only if there exists some coalition $D \supset C$ such that $C_{i}=D$ for all $i \in C$. Finally, in the sequential game of coalition formation, players are ordered according to an exogenous protocol. The first player announces a coalition that she wants to form. If all members agree, the coalition is formed and the next player (in the remaining set of players) gets to make an offer. If one member of the coalition rejects, she becomes the counter proposer next period. In this sequential game, it is natural to focus attention to the coalition structures generated by stationary perfect equilibria of the game. Finally, the model of farsighted coalition formation of Chwe (1984) can be applied to define alliance structures which are immune to farsighted deviations by the players.

\subsection{Endogenous alliance formation in conflict}

The analysis of endogenous alliance formation requires a full specification of the players' utilities, and can only be undertaken in the few instances where the model of group conflict admits a closed form solution. In order to obtain an exact closed form equilibrium solution, we will suppose, as Garfinkel (2004) and Sanchez-Pages (2007) that players face a linear investment technology, $c(s)=s$, and that the sharing rule is given by $V(a)=a^{\rho}$, with $-2 \leq \rho \leq 1 .^{7}$ With this cost specification, large groups may be inactive in equilibrium, and we first need to characterize the set of active players in the game. Following Hillman and Riley (1989) and Sanchez Pages (2007), we order the alliances by increasing size, $a_{1} \leq a_{2} \leq a_{3} \ldots \leq a_{m}$. If $\rho>0$, larger alliances are more likely to be active, and in equilibrium, alliances $A_{\kappa}, \ldots, A_{m}$ are active where:

$$
\kappa=\min \left\{k, a_{k}^{\rho} \geq(m-k-2) \sum_{j=k+1}^{m} a_{j}^{-\rho}\right\} .
$$

If $\rho<0$, on the contrary, small alliances are more likely to be active and in equilibrium, alliances $A_{1}, \ldots, A_{\kappa}$ are active where:

$$
\kappa=\max \left\{k, a_{k}^{\rho} \geq(k-2) \sum_{j=1}^{k-1} a_{j}^{-\rho}\right\} .
$$

\subsection{Stability of the grand coalition and of single alliance structures}

Let $U_{i}(\mathcal{A})$ denote the equilibrium payoff of player $i$ when the alliance structure $\mathcal{A}$ is formed. Immediate computations show that:

\footnotetext{
${ }^{7}$ Bloch et al. (2006) consider an alternative specification for which closed form solutions can be computed: they suppose a quadratic $\operatorname{cost} c(s)=\frac{1}{2} s^{2}$ and an egalitarian sharing rule, $V(a)=\frac{1}{a}$. Esteban and Ray (1999) also provide exact computations when $V(a)=v$ is independent of $a$, and $c(s)=s^{\alpha}$ is an iso-elastic cost function.
} 


$$
\begin{aligned}
U_{i}(\{N\}) & =n^{\rho} \\
U_{i}(\{1|1| \ldots \mid\}) & =n^{-2}, \\
U_{i}(\{i \mid N \backslash i\}) & =\frac{1}{\left(1+(n-1)^{\rho}\right)^{2}} .
\end{aligned}
$$

By comparing the equilibrium payoff of a player in the grand coalition with the utility she would obtain in the alliance of singletons and when she faces an alliance of $n-1$ players, we derive conditions under which the grand coalition is stable.

Proposition 4 The grand coalition, $\mathcal{A}=\{N\}$ is always an equilibrium of the $\gamma$ game of alliance formation. If $\rho \log n+2 \log \left(\left(1+(n-1)^{\rho}\right)\right) \geq 0$, the grand coalition is also an equilibrium of the open membership game and of the $\delta$ game of alliance formation.

Because we assume $\rho \geq-2$, players in the grand coalition can never do worse than if they fight as singletons: the peaceful grand coalition is thus always an equilibrium outcome if players anticipate that the coalition collapses into singletons after the departure of a member. If, on the other hand, players anticipate that other coalition members stick together after they leave, the grand coalition still remains an equilibrium if $\rho$ is large enough. Players have no incentive to leave the grand coalition and start a conflict as a singleton facing an alliance of $n-1$ members if $\rho \geq \rho^{*}(n)$, where $\rho^{*}(n)$ is implicitly defined by: $\rho \log n+2 \log \left(\left(1+(n-1)^{\rho}\right)\right) \geq 0$. Notice that, as $2 \log 2>0$, and $\log (n-1)-\log n<0$, we have $-1 \leq \rho^{*}(n) \leq 0$. Furthermore, $\rho^{*^{\prime}}(n)>0$ and $\lim _{n \rightarrow \infty} \rho^{*}(n)=0$, reflecting the fact that free-riding incentives are higher in larger societies, and the grand coalition can only remain stable if the sharing rule does not decrease too fast.

We now consider an arbitrary single alliance structure, with one alliance $A$ of size $a$ and $n-a$ singleton players. Simple computations show that the utility of an independent player, $U_{i}$ and of an alliance member, $U_{a}$ are given by:

$$
\begin{aligned}
U_{i} & =\frac{1}{\left(1+k^{\rho}(n-k)\right)^{2}}, \\
U_{a} & =\frac{k^{\rho-1}\left(k^{\rho}(n-k)-(n-k-1)\right)\left(k^{\rho+1}(n-k)-n+2 k\right)}{\left(k^{\rho}(n-k)+1\right)^{2}}
\end{aligned}
$$

if $k^{\rho}(n-k)-(n-k-1) \geq 0$ and $U_{i}=\frac{1}{(n-a)^{2}}, U_{a}=0$ otherwise. We first compare the utility of a member of an alliance with the utility of a player in the singleton structure, and note that $U_{a}$ is strictly increasing in $\rho$, whenever $k^{\rho}(n-k)-(n-k-1) \geq 0$ to obtain the following Proposition: 
Proposition 5 For any $n$ and any alliance size $2 \leq a \leq n-1$, there exists $\rho^{*}(a, n) \in$ $(-1,0)$ such that the alliance structure $\{A|1| \ldots \mid 1\}$ is an equilibrium of the $\gamma$ game of coalition formation if and only if $\rho \geq \rho^{*}(a, n)$. Furthermore, $\rho^{*}(a, n)$ is not monotonic in a.

Proposition 5 fully characterizes the set of alliances which are $\gamma$ stable. If $\rho<-1$, the only $\gamma$ stable structure is the grand coalition. If $\rho>0$, free-riding never occurs and any alliance structure can be sustained as an equilibrium of the $\gamma$ game. For $\rho \in(-1,0)$, different alliance structures may turn out to be $\gamma$-stable. The fact that $\rho^{*}(a, n)$ is not monotonic in $a$ is illustrated by the following example.

Example 1 Let $n=10$. The threshold values of $\rho$ are given by the following table:

\begin{tabular}{|c|c|}
\hline$a$ & $\rho^{*}(a)$ \\
\hline 2 & -0.1563 \\
\hline 3 & -0.1221 \\
\hline 4 & -0.1179 \\
\hline 5 & -0.1267 \\
\hline 6 & -0.1521 \\
\hline 7 & -0.1957 \\
\hline 8 & -0.3112 \\
\hline 9 & -1 \\
\hline
\end{tabular}

In order to investigate which alliances are $\delta$ stable, we need to consider a player's incentive to leave an alliance in the alliance structure $\{A|1| . . \mid 1\}$ in order to be an independent in the alliance structure $\{A \backslash i|1| \ldots \mid 1\}$,

$$
\begin{aligned}
\Delta(\rho, a, n) \equiv & \frac{1}{\left(1+(k-1)^{\rho}(n-k+1)\right)^{2}} \\
& -\frac{k^{\rho-1}\left(k^{\rho}(n-k)-(n-k-1)\right)\left(k^{\rho+1}(n-k)-n+2 k\right)}{\left(k^{\rho}(n-k)+1\right)^{2}}
\end{aligned}
$$

It is easy to check that for all $a$ and $n, \Delta$ is decreasing in $\rho$ (individual players have a stronger incentive to leave the alliance when the sharing rule becomes more convex) and $\frac{1}{\left(1+(k-1)^{\rho}(n-k+1)\right)^{2}} \geq \frac{1}{n^{2}}$ (individual players have a stronger incentive to leave the alliance when the other alliance members remain together). Hence, we obtain:

Proposition 6 For any $n$ and any alliance size $2 \leq a \leq n-1$, there exists $\tilde{\rho}(a, n) \in(-1,0)$ with $\tilde{\rho}(a, n)>\rho^{*}(a, n)$ such that the alliance structure $\{A|1| \ldots \mid 1\}$ is an equilibrium of the $\delta$ game of coalition formation if and only if $\rho \geq \tilde{\rho}(a, n)$. Furthermore, $\tilde{\rho}(a, n)$ is not monotonic in a. 
Example 2 Let $n=10$. Approximate values of the threshold level $\tilde{\rho}$ are given in the following table:

\begin{tabular}{|c|c|}
\hline$a$ & $\tilde{\rho}(a)$ \\
\hline 2 & -0.155 \\
\hline 3 & -0.115 \\
\hline 4 & -0.105 \\
\hline 5 & -0.11 \\
\hline 6 & -0.12 \\
\hline 7 & -0.14 \\
\hline 8 & -0.15 \\
\hline 9 & -0.16 \\
\hline
\end{tabular}

In an open membership game, an alliance $A$ is an equilibrium outcome if and only if no member of $A$ wants to leave the coalition, taking the strategies of the other players as given, and no other player has an incentive to join the alliance. These two conditions easily translate into: $\Delta(\rho, a, n)>0$ and $\Delta(\rho, a+1, n)<0$. Given Proposition 6, an alliance of size $a$ is an equilibrium outcome of the open membership game if and only if $\tilde{\rho}(a+1, n) \geq \rho \geq \tilde{\rho}(a, n)$. Because $\tilde{\rho}(a, n)$ is not monotonic in $a$, there exist alliance structures which are never reached as equilibrium outcomes of the open membership game. In the example with ten players, $\tilde{\rho}(a, n)$ is only increasing for $a=2,3$ and 4 , so that the only alliances which can be formed at the equilibrium of the open membership game are small alliances of sizes 2 and 3.

\subsection{Alliance formation with farsighted players}

The open membership and $\gamma$ and $\delta$ models of alliance formation assume that agents have limited foresight, and do not consider the long term consequences of their behavior. By contrast, the sequential game of coalition formation models players as farsighted agents who anticipate the consequences of their decisions on subsequent players. As a finite game with perfect information, barring non-generic indifferences, the sequential model of coalition formation admits a unique equilibrium alliance structure. However, this unique alliance structure is typically hard to compute, as it requires a complete characterization of optimal strategies in all the subgames generated by the decisions of the players. A complete characterization of equilibrium coalition structures can only be achieved in some special cases. ${ }^{8}$

Suppose for example that $\rho=0$, so that every agent obtains $V(a)=1$ in any alliance. In this case, it is easy to see that, by forming the grand coalition, players achieve the payoff of 1 , whereas in any other alliance structure they obtain a lower payoff, as they receive the prize of 1 with probability $p<1$ and must furthermore

\footnotetext{
${ }^{8}$ The following discussion is based on Sanchez-Pages (2007).
} 
expand resources on conflict. Hence the grand coalition is the unique subgame perfect equilibrium outcome of the sequential game of alliance formation.

If the payoff is equally shared among all coalition members, $\rho=1$, the equilibrium utility is given by:

$$
\begin{aligned}
U_{i}(\mathcal{A}) & =\frac{V}{a_{i} n^{2}}\left(n-a_{i}(\kappa-1)\right)(n-(\kappa-1)) \text { if } a_{i} \leq \frac{n}{\kappa-1}, \\
U_{i}(\mathcal{A}) & =0 \text { otherwise. }
\end{aligned}
$$

We will show that, as long as $\kappa \geq 1$ and the number of active players satisfies $s<n-1$, the optimal strategy of every player is to announce the formation of a singleton. The result is obviously true for the last player, $n$. Consider a situation where $\kappa \geq 1, s<n-1$, and such that all players form singletons after any move by player $n-s+1$. The maximization problem of player $n-s+1$ can thus be written:

$$
\max _{a} \frac{1}{a}(n-a(\kappa+s-a))(n-(\kappa+s-a)) .
$$

It is easy to check that, as long as $\kappa \geq 1$ and $s+\kappa<n$,

$$
\begin{aligned}
& (n-a(\kappa+s-a))<n-(s+\kappa-1), \\
& \frac{1}{a}(n-(\kappa+s-a))<n-(s+\kappa-1),
\end{aligned}
$$

establishing the result. This induction argument allows us to show that all players form singletons in any subgame following the formation of a coalition if $s<n-1$. If $s=n-1$ and $\kappa=1$, player 2 is indifferent between forming a singleton or a coalition of size $n-1$. (She would strictly prefer to form a singleton if $\rho<-1$, and strictly prefer to form an alliance of size $n-1$ if $\rho>-1$.) We conclude that there are two subgame perfect equilibria: one where the first player forms a singleton and the second player a coalition of size $n-1$ and one where the first player forms the grand coalition.

Finally, consider the model with $\rho=-2$, where players inside a coalition of size $a$ obtain the payoff $V(a)=\frac{1}{a^{2}}$, corresponding to the equilibrium payoff of a subsequent contest among members of the alliance. We will show again by induction that, after the formation of $\kappa \geq 1$ coalitions, every player's optimal strategy is to form a singleton. The result is obviously true for player $n$, so we consider the choice of player $n-s$ after $\kappa$ coalitions are formed. By a simple computation, we check that, if to players form singletons, any other alliance of size $a \geq 2$ is inactive. We can also check that, among active alliances, smaller alliances invest more and have a higher probability of winning the contest.

If two players have formed singletons before $n-s$ moves, player $n-s$ 's optimal strategy is thus also to form a singleton. If one player has already formed a singleton, 
player $n-s$ has the choice between two strategies: form a singleton (and get a payoff of $\frac{1}{(s+1)^{2}}$, or form a single alliance of size $s$, which wins the contest with probability $p<\frac{1}{2}$, resulting in a payoff smaller than $\frac{1}{2 s^{2}}$. As $s \geq 2,2 s^{2}>(s+1)^{2}$, and player $n-s$ 's optimal choice is to form a singleton. Finally, suppose that no singleton has formed before player $n-s$. If player $n-s$ forms an alliance of size $a<s-2$, it will be followed by two singletons, and be inactive. If it forms an alliance of size $s$, it will obtain a payoff smaller than $\frac{1}{s^{2}}$. If it forms an alliance of size $s-1>1$, it will be followed by a singleton and obtain a payoff smaller than $\frac{1}{2(s-1)^{2}}$. If it forms a singleton, it will obtain a payoff $\frac{1}{s^{2}}$. Hence, forming a singleton is an optimal strategy for player $n-s$. The first player in the game will be indifferent between forming a singleton or the grand coalition, as both will result in the same payoff of $\frac{1}{n^{2}}$. However, if $\rho>-2$, the grand coalition dominates the partition of singletons and the first player will choose to form the alliance $N$.

Summarizing the preceding findings, the following graph shows equilibrium alliance structures for different values of $\rho$.

\begin{tabular}{ccc}
$\{\mathrm{N}\}$ & $|\{\mathrm{N}\}|\{1 \mid \mathrm{N} \backslash 1\}$ & $\mid\{\mathrm{N}\}$ \\
\hline-2 & -1 & 0
\end{tabular}

Figure 2: Equilibrium ALLIANCE STRUCtures in the SEQUential game

Figure 2 displays some gaps - parameter regions where the equilibrium coalition 
structure cannot be determined. ${ }^{9}$ Interestingly, it shows that the grand coalition is the equilibrium alliance structure both for high and low values of $\rho$. For high values of $\rho$, this is due to the fact that the grand coalition dominates any other alliance structure ; for low values of $\rho$, to the fact that any move by the first player will be followed by the formation of singletons, so that the first player effectively chooses between forming the grand coalition or the structure of singletons. ${ }^{10}$

Garfinkel (2004) studies the model with $V(a)=\frac{1}{a^{2}}$ using a different equilibrium concept, inspired by Chwe (1994)'s notion of farsighted dominance. She finds that any symmetric equilibrium structure, with $\mathcal{A}$ a collection of alliances of size $\frac{n}{k}$ is stable, as well as coalition structures comprised of coalitions which are "almost symmetric". The intuition underlying this result is as follows. If any player deviates to form a singleton, this will trigger the formation of the coalition of singletons, where the deviator gets a payoff $\frac{1}{n^{2}}<\frac{1}{k\left(\frac{n}{k}\right)^{2}}=\frac{k}{n^{2}}$. Hence, a deviation to leave a coalition is not profitable. Furthermore, in the model members of large alliances have lower payoffs. This implies that players have no incentive to deviate by joining an existing coalition which would be larger than the one she they leave, because in the symmetric alliance all alliances initially have the same size.

\section{Endogenous Sharing rules and Asymmetric Agents}

\subsection{Endogenous sharing rules}

We have assumed so far that the sharing rule in each alliance is independent of the investments of the players. Alternatively, we could have considered situations where the effort of each player in the inter-alliance conflict affects the sharing of the prize among alliance members. Nitzan (1991a) offered the first specification of a group contest with a sharing rule depending on investments in conflict. In his model, the share of the prize obtained by an agent $i$ in alliance $A$ is given by:

$$
f_{i}\left(s_{1}, . ., s_{n}\right)=(1-\alpha) \frac{s_{i}}{\sum_{j \in A} s_{j}}+\alpha \frac{1}{a} .
$$

The sharing rule is a convex combination of the egalitarian sharing rule, and the relative effort rule which is proportional to every agent's investment in conflict. Under this sharing rule, agent $i$ in alliance $A$ receives an expected utility

$$
U_{i}=(1-\alpha) \frac{s_{i}}{\sum_{j} s_{j}}+\alpha \frac{\sum_{j \in A} s_{j}}{a \sum_{j} s_{j}}-c\left(s_{i}\right) .
$$

When $\alpha=0$, the contest is exactly identical to a contest where all agents are singletons and the formation of groups is irrelevant. In the other polar case, where

\footnotetext{
${ }^{9}$ However, we conjecture that $\{N\}$ remains the equilibrium structure for all $\rho \in(-2,-1)$.

${ }^{10}$ The grand coalition also emerges as the unique equilibrium alliance structure in the model of Bloch et al. (2006), where $V(a)=\frac{1}{a}$ and players incur a quadratic cost.
} 
$\alpha=1$, the conflict is equivalent to a group conflict with sharing rule $V(a)=\frac{1}{a}$, as in Section 2. When a group of size $a$ faces $n-a$ independent players, denoting by $s_{a}$ and $s_{i}$ the individual efforts of group members respectively, the best response maps are given by:

$$
\begin{aligned}
(1-\alpha)(a-1) s_{1}+(n-a) s_{i} & =\left(a s_{a}+(n-a) s_{i}\right)^{2} \\
a s_{a} & =\left(a s_{a}+(n-a) s_{i}\right)^{2}
\end{aligned}
$$

The best response map of group members, $\phi_{a}\left(s_{i}\right)$ is decreasing in $\alpha$ while the best response map of independents, $\phi_{i}\left(s_{a}\right)$ is independent of $\alpha$. When $\alpha$ increases, the investment of group members decreases, while the investment of independent players goes up. Lower values of $\alpha$ correspond to a more aggressive behavior of the group, and results in higher investments for the alliance, and a higher probability to win the conflict. This result is easily understood. By increasing the weight placed on relative investments, the alliance induces agents to spend more on conflict, as in a "rat race" where an agent's payoff depends on his effort relative to the group. Hence, as noted by Nitzan (1991a), an increase in $\alpha$ reduces total investment in conflict.

Nitzan (1991a)'s analysis treats the sharing rule as exogenous. Baik and Shogren (1995), Lee (1995) and Baik and Lee (1997) consider the endogenous determination of the weight $\alpha$ which maximizes the expected payoff of the group, and discuss different models of alliance stability. In Baik and Shogren (1995), a single group of size $a$ faces a collection of singletons. In that case, in an interior equilibrium, the optimal sharing rule is given by:

$$
\alpha^{*}=1-\frac{2 a n-2 a^{2}-n}{2(a-1)(n-1)} .
$$

We observe that $\alpha^{*}$ is decreasing in $a$. For larger groups, the "rat race" results in overspending on conflict, and the optimal investments are obtained when the group uses an egalitarian sharing rule. Given the optimal sharing rule, one can compute the equilibrium payoff of a member and a nonmember. The following diagram illustrates how members and nonmember's payoffs depend on $a$.

Finally, Baik and Shogren (1995) analyze the endogenous formation of the alliance in an open membership game. They observe that when $a>\frac{n}{2}$, agents have an incentive to leave the group and form singletons. When, on the other hand, $a<\frac{n}{2}$, group members obtain a higher payoff than independent players. Hence, the equilibrium group size is the smallest integer higher than $\frac{n}{2}$.

Lee (1995) and Baik and Lee (1995) analyze endogenous sharing rules chosen strategically by two groups in a two-stage model where groups simultaneously choose the parameter $\alpha_{i}$ of the sharing rule in the first stage, and compete in an interalliance conflict in the second stage. ${ }^{11}$ Consider the following simplified version of

\footnotetext{
${ }^{11}$ Nitzan (1991b) initially observed that, when the two groups choose different sharing rules,
} 


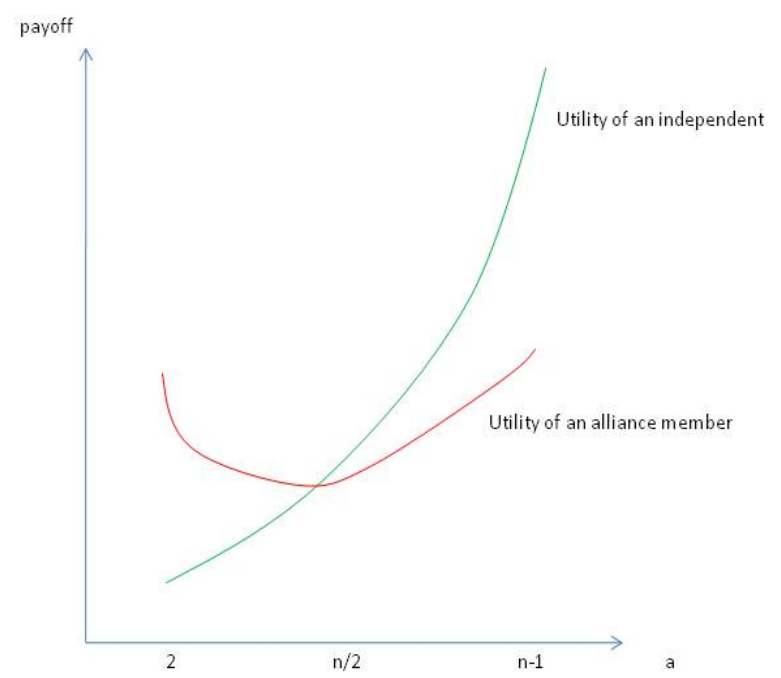

Figure 3: PAYOFF OF INDEPENDENT AND ALLIANCE MEMBERS WITH OPTIMAL SHARING RULE

Lee (1995)'s setup where two groups of equal size $a_{1}=a_{2}=\frac{n}{2}$ choose between the relative effort $(\alpha=0)$ and egalitarian $(\alpha=1)$ rules. Simple computations of the equilibrium levels of conflict and utilities following any choice $\left(\alpha_{1}, \alpha_{2}\right)$ of the two firms allow us to draw the following matrix to study the game played by the two groups in the initial stage.

\begin{tabular}{|c|c|c|}
\hline & $\alpha_{2}=0$, & $\alpha_{2}=1$ \\
\hline$\alpha_{1}=0$ & $\left(\frac{1}{n^{2}}, \frac{1}{n^{2}}\right)$ & $\left(\frac{4}{n+2}^{2}, \frac{8}{n(n+2)^{2}}\right)$ \\
\hline$\alpha_{1}=1$ & $\left(\frac{8}{n(n+2)^{2}}, \frac{4}{n+2}^{2}\right)$ & $\left(\frac{1}{2 n}, \frac{1}{2 n}\right)$ \\
\hline
\end{tabular}

This game has the structure of a prisoner's dilemma. Both groups have a dominant strategy: to choose the aggressive relative effort rule, $\alpha=0$, even though they would both be better off selecting the softer egalitarian rule, $\alpha=1$. Lee (1995) generalizes this intuition to any choice of $\alpha \in[0,1]$ and observes that, if two alliances

interior pure strategy equilibria may not exist. Davis and Reilly (1999) later observed that an equilibrium always exists, but may involve some groups choosing zero investment and retiring from the contest. 
of equal size are formed, the only equilibrium is for both groups to choose the most aggressive sharing rule, setting $\alpha$ to 0 . On the other hand, if the groups are of different sizes (and negative values of $\alpha$ are allowed), Baik and Lee (1997) show that the two groups are likely to adopt different sharing rules, with the smaller group adopting a more aggressive sharing strategy $(\alpha=0)$, while the larger group favors a more balanced sharing rule $(\alpha>0)$. Furthermore, if players initially engage in an open membership alliance formation game where multiple alliances can be formed, alliance sizes are similar to those derived by Baik and Shogren (1995) when a single alliance forms. Two alliances of sizes approximately equal to $\frac{n}{2}$ will emerge at equilibrium.

The initial analysis of Nitzan (1991a) and Baik and Shogren (1995) and Lee (1995) focussed on interior equilibria and ignored the possibility that some group optimally choose not to participate in the contest. Ueda (2002) corrects this bias by characterizing all equilibria of Nitzan (1991a)'s contest model including corner equilibria. He provides exact conditions under which "oligopolization" occurs, namely the fact that some groups endogenously choose to retire from the contest. Ueda (2002) also characterizes the equilibria of a two-stage model where alliances endogenously choose their sharing rule in the first stage and compete in the second. When no group has a size greater than half of the population, he shows that all groups adopt the relative effort rule $(\alpha=0)$ in equilibrium. If one large alliance groups more than half of the population, the large alliance will use a softer rule $(\alpha>0)$, whereas all small alliances keep choosing the aggressive relative effort rule.

\subsection{Asymmetric agents}

In all the models considered so far, the only source of asymmetry among players is the difference in the sizes of the alliances they belong to. Other sources of heterogeneity among agents could be considered: agents can differ in their effort cost, or (equivalently) in the productivity of their efforts, or in the amount of resources that they can spend in conflict. Noh (1999) and (2002) analyzes a model with endogenous sharing rules among asymmetric players. Agents are endowed with heterogeneous resources, $R_{i}$ that they can either spend in conflict $\left(s_{i}\right)$ or for productive purposes $\left(p_{i}\right)$. The productive technology is assumed to be linear, and the total prize is given by:

$$
V=\sum_{j} p_{j}=\sum_{j} R_{j}-s_{j}
$$

The two groups compete for the prize, which is shared according to Nitzan(1991a)'s rule. The expected utility of agent $i$ is thus given by

$$
U_{i}=\left((1-\alpha) \frac{s_{i}}{\sum_{j} s_{j}}+\alpha \frac{\sum_{j \in A} s_{j}}{a \sum_{j} s_{j}}\right)\left(\sum_{j} R_{j}-s_{j}\right) .
$$


Noh (1999) analyzes a two-group contest and shows that, contrary to Lee (1995), this specification of the contest either leads the two groups to choose the egalitarian rule, or a small group to choose the relative effort rule while the large group selects $\alpha \in(0,1)$. The contrast between Noh (1999)'s and Lee (1995)'s result stems from the fact that in Noh (1999)'s model, more aggressive behavior of the two groups reduces the common pool, resulting in lower utilities for the group members.

Noh (2002) extends the analysis to a three-player contest with $R_{1} \geq R_{2} \geq R_{3}$ and assumes that the formation of an alliance increases the effectiveness of conflict investments for the two alliance members. The analysis distinguishes between a number of different cases. The general message of the paper can be summarized as follows. When alliance formation enhances the effectiveness of the members' appropriation efforts, the two better endowed agents form an alliance, maintain the value of the common pool at a high level and fight to prevent the poorest agent from appropriating the resource. When alliance formation only results in moderate gains in the effectiveness of conflict efforts, the two poorest agents form an alliance.

\section{Dynamic alliance formation}

\subsection{Dynamic alliance formation with exogenous effort}

The models analyzed so far assume that the prize is shared among alliance members once and for all according to a sharing rule $V(a)$ or $V(a, \mathbf{s})$. Even when players are assumed to fight inside the alliance to obtain the prize (and obtain for example $V(a)=\frac{1}{a^{2}}$ when the investment cost is linear), the intra-alliance contest is supposed to be final. There is no room for further sub-alliance formation inside the alliance, and the conflict ends after two stages.

This specification of conflict misses an important element of alliance formation, and introduces an asymmetry between a first stage conflict (where alliances can be formed) and a second-stage conflict (where sub-alliances cannot be formed). By contrast, models of continuing conflict (or equivalently "nested contests") analyze alliance formation and conflict as a dynamic process, resulting in the successive elimination of players, until the final contest is played between the last two players.

In order to understand the dynamics of conflict and alliance formation, we focus on a model with three agents $i=1,2,3$. Each agent has a fixed, exogenous endowment $y_{i}$. The probability of winning the contest is exogenously given by

$$
p_{i}=\frac{y_{i}}{\sum_{j} y_{j}} .
$$

At the initial stage, either the three players compete as singletons, or an alliance of two players is formed. If the alliance wins the contest, its two members subsequently compete to obtain the prize. ${ }^{12}$ We compare the utility obtained by player 1

\footnotetext{
${ }^{12}$ With three players, the continuing conflict model is identical to the two-stage model with one
} 
in the overall contest and when she forms an alliance with player 2. In the first case, she obtains

$$
U_{1}=V \frac{y_{1}}{y_{1}+y_{2}+y_{3}}
$$

and in the second

$$
U_{1}^{\prime}=V \frac{y_{1}+y_{2}}{y_{1}+y_{2}+y_{3}} \frac{y_{1}}{y_{1}+y_{2}}=U_{1}
$$

It thus appears that players have no incentive to form an alliance. Konrad (2009) labels this result "the paradox of alliance formation".

In order to allow for synergies in the investments of the two alliance members, we consider an increasing mapping $f\left(y_{i}\right)$ such that the probability of winning the contest is given by:

$$
p_{i}=\frac{f\left(y_{i}\right)}{\sum_{j} f\left(y_{j}\right)} .
$$

In this model, an alliance between two players will be formed if and only if the mapping $f$ is superadditive, namely $f\left(y_{i}+y_{j}\right)>f\left(y_{i}\right)+f\left(y_{j}\right)$ for all $y_{i}, y_{j}$. Two frequently used functional forms are the probit and logit specifications:

$$
\begin{aligned}
& f_{i}\left(y_{i}\right)=y_{i}^{m}, \\
& f_{i}\left(y_{i}\right)=e^{k y_{i}} .
\end{aligned}
$$

Skaperdas (1998) provides general conditions under which the alliance if formed by the two stronger or weaker players. In particular, he notes that for the probit specification, the alliance will always be formed among the two weakest players. For the logit model, the alliance will be formed among the weakest players if and only if:

$$
\begin{aligned}
H\left(y_{1}, y_{2}, y_{3}\right) & =e^{k\left(y_{1}+y_{2}+y_{3}\right)}-e^{k\left(y_{1}+y_{2}\right)}-e^{k\left(y_{1}+y_{3}\right)}-e^{k\left(y_{2}+y_{3}\right)} \\
& \geq 0
\end{aligned}
$$

Tan and Wang (1997) independently analyze the formation of alliances among free players and obtain essentially the same result, showing that the two weak players form an alliance for the probit model and when $f(y)=\exp \gamma y-1$. They note that the strong player may not have the highest probability of winning the contest (taking for example, $f(y)=y^{2}, y_{1}=0.6, y_{2}=0.5$ and $y_{3}=0.2$, the winning probabilities of the three players are $0.42,0.5$ and 0.08 respectively.) Moving to the more complex case of four players with $y_{1}>y_{2}>y_{3}>y_{4}$, Tan and Wang (1997) show that if

stage of inter-alliance and one stage of intra-alliance conflict. The difference between the models would only appear with more than three players. 
$y_{1}>y_{3}+y_{4}$, the unique equilibrium coalition structure is $\{1 \mid 234\}$ followed by $\{2 \mid 34\}$ if the alliance 234 wins. Hence, at each stage, the weakest players form an alliance against the strongest player. ${ }^{13}$ If $y_{1}<y_{3}+y_{4}$, the unique equilibrium coalition structure is of the form $\{i j \mid k l\}$, with two alliances of two players.

\subsection{Dynamic alliance formation with endogenous effort}

Consider now a situation where players endogenously choose their level of effort. The first result on hierarchical contest, due to Wärneryd (1998) shows that the total level of resources spent on conflict is lower in a hierarchical conflict than in a single, simultaneous conflict. Consider a conflict with linear costs among inhabitants of two regions, labeled $A$ and $B$ with sizes $n_{A}$ and $n_{B}$. In a simultaneous conflict, the total expenditures on conflict are $\delta^{S}=V \frac{n_{A}+n_{B}-1}{n_{A}+n_{B}}$. Consider next a two-stage conflict where the two regions fight in the first stage, and members of the winning region subsequently fight to obtain the prize. The second stage payoff in the two regions are $\frac{1}{n_{A}^{2}}$ and $\frac{1}{n_{B}^{2}}$, so that the expected resources spent on conflict are

$$
\delta^{H}=V\left(\frac{n_{A}^{2}+n_{B}^{2}}{\left(n_{A}^{2}+n_{B}^{2}\right)^{2}}+\frac{n_{A}^{2}}{n_{A}^{2}+n_{B}^{2}} \frac{n_{B}-1}{n_{B}}+\frac{n_{B}^{2}}{n_{A}^{2}+n_{B}^{2}} \frac{n_{A}-1}{n_{A}}\right)<\delta^{S} .
$$

establishing that total rent dissipation is lower in a hierarchical contest. This result is easily explained. In a hierarchical contest, resources spent in the first-stage contest are lower because players only obtain a fraction of the prize if they win. In the second-stage contest, fewer players are involved and the amount of resources spent on conflict is reduced accordingly.

Esteban and Sakovics (2003) analyze a similar model among three groups with a quadratic investment cost. They obtain a negative result: free-riding incentives are so strong that alliances of two players will never form. This new instance of "the paradox of alliance formation" illustrates the two forces which hinder the formation of coalitions in models of conflict. On the one hand, even if effort was exogenous, players would not have an incentive to form coalitions unless the effort levels of the two partners exhibit some synergies. On the other hand, when effort choice is endogenous, free-riding in the coalition lowers the incentives to provide effort, and reduces the winning probability of the alliance. Both effects concur in making the formation of an alliance unprofitable.

\subsection{Dynamic alliance formation with budget constraints}

Kovenock and Konrad (2008) reexamine the alliance formation puzzle, in a discriminating contest without noise, as in Hillman and Riley (1989) and Baye, Kovenock and de Vries (1996). Let the three players have budget constraints $b_{1}, b_{2}$ and $b_{3}$, with $b_{1}>b_{2}=b_{3}$. In the all-pay auction, every player chooses an investment level

\footnotetext{
${ }^{13}$ This result generalizes to the case of $n$ players when $y_{i}>\sum_{k=i+1}^{n} y_{k}$ for all $i$.
} 
$s_{i} \in\left[0, b_{i}\right]$ and player $i$ wins with probability 1 if $s_{i}>\max \left\{s_{j}, s_{k}\right\}$, with probability 0 if $s_{i}<\max \left\{s_{j}, s_{k}\right\}$ and with probability $\frac{1}{m}$ if $m$ players choose the same effort level $s_{i}$. In this context, there is an equilibrium where the strongest player, player 1 has an expected payoff $U_{1}=b_{1}-b_{2}$, while the weakest players have an expected payoff $U_{2}=U_{3}=0$.

Next, consider a situation where players 2 and 3 initially pool their efforts (and choose a common effort level $s_{23}$ in response to $s_{1}$ ), and then compete against each other in a second stage if they win the first stage contest. In this game, when $b_{2} \in\left(\frac{b_{1}}{2}, \frac{1-b_{1}}{2}\right)$, Kovenock and Konrad (2008) prove existence of a subgame perfect

equilibrium with expected payoffs $U_{1}=0, U_{2}=U_{3}=\frac{1-b_{1}-2 b_{2}}{2}$. Hence, contrary to Esteban and Sakovics (2003), the two weak players have an incentive to form an alliance and obtain a higher payoff than the strong player in a contest without noise.

\section{Conclusion}

This paper has highlighted how recent advances in game theory (on coalition formation, all-pay auctions, comparative statics in games) have helped further our understanding of alliance formation in conflict. A number of questions remain open for future research.

First, the analysis of sharing rules has so far been restricted to convex combinations of the egalitarian and relative effort rules. While this specification of sharing rules as a one-parameter family is useful as a first step, one wonders whether the introduction of more general sharing rules wouldn't help our understanding of the interaction between group conflict and internal sharing rules. Second, the current analysis of dynamic contests has been limited to three players, and has assumed that players have access to the same resources in the first and second stage of the contest. Generalizing the results to contests with an arbitrary number of players is a challenging task, but it should be undertaken in the future. Furthermore, one should also consider nested contests where players make decisions on the way in which they share fixed resources among successive contests. Third, while the literature has focused on free-riding problems in alliances, it has not yet analyzed in detail incentive contracts for alliance members. As every alliance faces a moral hazard problem, allowing a principal to offer a contract in each alliance seems natural. This would lead to a study of the interaction between inter-alliance conflict and intra-alliance contracts, and how this interaction affects the endogenous choice of group sizes. Finally, the analysis of alliance formation so far has supposed that agents live in a world of complete information, and know perfectly each other's strength in conflict. In reality, different alliance members may have private information about their types (conflict technology and/or payoffs), leading to the study of alliance formation as a game of incomplete information. 


\section{References}

1. Baik, K. H. and J. Shogren (1995) "Competitive-share group formation in rentseeking contests," Public Choice 83, 113-126.

2. Baik, K. H. and S. Lee (1997) "Collective rent seeking with endogenous group sizes," European Journal of Political Economy 13, 121-130.

3. Baye, M., D. Kovenock and C. de Vries (1996) "The all-pay auction with complete information," Economic Theory 8, 362-380.

4. Bloch, F. (1996) "Sequential formation of coalitions with externalities and fixed payoff division," Games and Economic Behavior 14, 90-123.

5. Bloch, F., Sanchez-Pages, S. and R. Soubeyran (2006) "When does universal peace prevail? Secession and group formation in conflict," Economics of Governance 7, 3-29.

6. Chamberlin, J. (1974) "Provision of collective goods as a function of groups size," American Political Science Review 68, 707-716.

7. Davis, D.D. and R. J. Reilly (1999)"Rent-seeking with non-identical sharing rules: An equilibrium rescued," Public Choice 100, 31-38.

8. Dixit, A. (1986) "Comparative statics for oligopoly," International Economic Review 27, 107-122.

9. Esteban, J. and D. Ray (1999) "Conflict and distribution," Journal of Economic Theory 87, 379-415.

10. Esteban, J. and D. Ray (2001) "Collective action and the group size paradox," American Political Science Review 95, 663-672.

11. Esteban, J. and J. Sakovicz (2003) "Olson vs. Coase: Coalitional worth in conflict," Theory and Decision 55, 339-357.

12. Garfinkel, M. R. (2004) "Stable alliance formation in distributional conflict," European Journal of Political Economy 20, 829-852.

13. Hart, S. and M. Kurz (1983) "Endogenous formation of coalitions," Econometrica 51, 1047-1064.

14. Hillman, A. L. and J. G. Riley (1989) "Politically contestable rents and transfers," Economics and Politics 1, 17-39.

15. Katz, E. , S. Nitzan and J. Rosenberg (1990) "Rent seeking for pure public goods," Public Choice 65, 49-60. 
16. Katz, E. and J. Tokatlidu (1996) "Group competition for rents," European Journal of Political Economy 12, 599-607.

17. Konrad, K. A. (2009) Strategy and Dynamics in Contests, LSE Perspectives in Economic Analysis, Oxford University Press, Oxford UK.

18. Konrad, K.A. and D. Kovenock (2008) "The alliance formation puzzle and capacity constraints," CEPR Discussion Paper 6333

19. Lee, S. (1995) "Endogenous sharing rules in collective rent-seeking," Public Choice 85, 31-44.

20. Mac Guire, M. C. (1974) "Group size, group homogeneity and the aggregate provision of a public good under Cournot behavior," Public Choice 18, 107-126.

21. Nitzan, S. (1991a) "Collective rent dissipation," Economic Journal 101, 15221534 .

22. Nitzan, S. (1991b) "Rent-seeking with non-identical sharing rules," Public Choice 71, 43-50.

23. Noh, S.J (1999)"A general equilibrium model of two-group conflict with endogenous intra-group sharing rules," Public Choice 98, 251-267.

24. Noh, S.J (2002)"Resource distribution and stable alliances with endogenous sharing rules," European Journal of Political Economy 18, 129-151.

25. Olson, M. (1965) The Logic of Collective Action, Harvard University Press, Cambridge, MA.

26. Olson, M. and R. Zeckhauser (1966)"An economic theory of alliances," Review of Economics and Statistics 47, 266-279.

27. Ray, D. and R. Vohra (1999) "A theory of endogenous coalition structures," Games and Economic Behavior 26, 286-336.

28. Sandler, T. Collective Action: Theory and Applications, University of Michigan Press, Ann Arbor, MI.

29. Sandler, T. (1993) "The economic theory of alliances: a survey," Journal of Conflict Resolution 37, 446-483.

30. Sandler, T. and K. Hartley (2001) "Economics of alliances: The lessons for collective action," Journal of Economic Literature 39, 869-896.

31. Sanchez -Pages, S. (2007) "Endogenous coalition formation in contests," Review of Economic Design 11, 139-163. 
32. Skaperdas, S. (1996) "Contest success functions," Economic Theory 7, 283-290.

33. Skaperdas, S. (1998) "On the formation of alliances in conflicts and contests," Public Choice 96, 25-42.

34. Tan, G. and R. Wang (1997) "Endogenous coalition formation in rivalry," Queen's Economics Department Working paper 956, Queen's University, Kingston, ON, Canada.

35. Tullock, G. (1967) "The welfare costs of tariffs, monopolies and theft," Western Economic Journal 5, 224-232.

36. Tullock, G. (1980) "Efficient rent seeking," in Buchanan, J. , Tollison, R. and G. Tullock (eds.) Towards a theory of the rent seeking society, Texas A \& M University Press, College Station, TX.

37. Ueda K. (2002) "Oligopolization in collective rent-seeking," Social Choice and Welfare 19, 613-626.

38. Wärneryd K. (1998) "Distributional conflict and jurisdictional organization," Journal of Public Economics 69, 435-450.

39. Yi, S.S. (1997) "Stable coalition structures with externalities," Games and Economic Behavior 20, 201-237.

\section{Appendix}

Proof of Proposition 2: Define

$$
\begin{aligned}
F\left[a, S_{a}, S_{b}\right] & \equiv V(a) S_{b}-c^{\prime}\left(\frac{S_{a}}{a}\right) S^{2}, \\
G\left[a, S_{a}, S_{b}\right] & \equiv V(n-a) S_{a}-c^{\prime}\left(\frac{S_{b}}{n-a}\right) S^{2} .
\end{aligned}
$$

Next compute 


$$
\begin{aligned}
\frac{\partial F}{\partial S_{a}} & =-\frac{1}{a} c^{\prime \prime}\left(\frac{S_{a}}{a}\right) S^{2}-2 S c^{\prime}\left(\frac{S_{a}}{a}\right)<0, \\
\frac{\partial F}{\partial S_{b}} & =V(a)-2 c^{\prime}\left(\frac{S_{a}}{a}\right) S, \\
\frac{\partial F}{\partial a} & =V^{\prime}(a) S_{b}+\frac{S_{a}}{a^{2}} c^{\prime \prime}\left(\frac{S_{a}}{a}\right) S^{2}, \\
\frac{\partial G}{\partial S_{a}} & =V(n-a)-2 c^{\prime}\left(\frac{S_{b}}{n-a}\right) S, \\
\frac{\partial G}{\partial S_{b}} & =-\frac{1}{n-a} c^{\prime \prime}\left(\frac{S_{b}}{n-a}\right) S^{2}-2 S c^{\prime}\left(\frac{S_{b}}{n-a}\right)<0, \\
\frac{\partial G}{\partial a} & =-V^{\prime}(n-a)-\frac{S_{b}}{n-a} c^{\prime \prime}\left(\frac{S_{b}}{n-a}\right) S^{2} .
\end{aligned}
$$

If $S_{a}>S_{b}, \frac{\partial F}{\partial S_{b}}>0$ and $\frac{\partial G}{\partial S_{a}}<0$. Conversely, if $S_{a}<S_{b}, \frac{\partial F}{\partial S_{b}}<0$ and $\frac{\partial G}{\partial S_{a}}>0$. Hence, we have:

$$
\left|\begin{array}{ll}
\frac{\partial F}{\partial S_{a}} & \frac{\partial G}{\partial S_{q}} \\
\frac{\partial F}{\partial S_{b}} & \frac{\partial G}{\partial S_{b}}
\end{array}\right|>0
$$

Furthermore, if $\inf _{a} \frac{a V^{\prime}(a)}{V(a)} \geq \sup _{s} \frac{-s c^{\prime \prime}(s)}{s}, \frac{\partial F}{\partial a}>0$ and $\frac{\partial G}{\partial a}<0$. Recalling that $S_{a}=S_{n-a}$ when $a=n-a$, we conclude that, for $a \geq n-a$,

$$
\left|\begin{array}{ll}
\frac{\partial F}{\partial a} & \frac{\partial G}{\partial S_{a}} \\
\frac{\partial F}{\partial b} & \frac{\partial G}{\partial S_{b}}
\end{array}\right|>0
$$

so that $S_{a}$ is increasing in $a$. If, on the other hand, $\sup _{a} \frac{a V^{\prime}(a)}{V(a)} \leq \inf _{s} \frac{-s c^{\prime \prime}(s)}{s}, \frac{\partial F}{\partial a}<0$ and $\frac{\partial G}{\partial a}>0$, and a similar argument shows that $S_{a}$ is decreasing in $a$ for $a \leq n-a$. 